The Wratten $61 \mathrm{~N}$ red-free filters are employed in the usual way. At the suggestion of Dr. Margaret Dobson a special chromium screen is incorporated which utilises the foveal pigment to enhance the detail of the macular area. Any individual preferences in filters can be added quite simply, and the manufacturers will gladly give their assistance in any experimental work, scope for which is offered by the multiplicity of adjustments available.

\title{
EXTRACTION OF THORN FROM THE ORBITAL CAVITY
}

\author{
BY \\ S. N. KAUL, M.B., Ch.B.Edin. \\ LAHORE
}

BHag Din, 35 years of age, applied for help in Sir Ganga Ram Free Hospital, Lahore, August 6, 1927.

History. While hedging four months ago, a foreign body entered his right eye behind the upper lid in its inner third. He cannot say what kind of foreign body it was, but all he can say is that it entered like a shot. Since then nothing has been done in the way of treatment.

On examination there is slight oedema of the right upper lid, chemosis of conjunctiva, and slight proptosis of the right eyeball, with a pin point pupil which does not react to light and accommodation. Anterior chamber is deep. Fundus is not visible and the pupil does not dilate with atropine. There is no tenderness on palpating the eyeball, and the right upper lid cannot be everted, and no foreign body can be seen, but, with gentle palpation, some hardness can be felt about the inner third of the lid. R.V.= P.L.; $\mathrm{L} . \mathrm{V} .=6 / 8$.

Under chloroform anaesthesia on the same day, when the lid was everted, a blackish mass was seen to be projecting out from the region of the fornix. With a little manipulation of the toothed conjunctival forceps, this was taken out and proved to be a thorn, one and a quarter inches in length. No pus escaped on pressure. The thorn was exactly like the one shown by Dr. Shroff of Bombay, and the site where it entered the fornix also corresponded to the picture shown by him in the February, 1928, number of the Brit. Jl. of Ophthalmology.

August 12,192\%. Very clean and clear eye, very little discharge behind the lid. A couple of granulations are present; these were snipped off. Pupil is slightly dilated and shows some exudate in the lower half, but fundus reflex is still unobtainable. There is no pain in the eye and never has been since the day of the operation. 
August 14, 1928. Slight fundus reflex is present, but fundus details are not visible.

August 15, 1927. There is no conjunctival injection or proptosis. Although he cannot see, he is feeling well and wishes to be discharged. Having read Dr. Shroff's article in the February number of Brit. Jl. of Ophthal., I am tempted to put on record the above case which is like the one described by him. The points of difference being the long duration of time since the accident happened, till the time when he applied for help, and the consequent iritis with seclusion and occlusion of the pupil. It is remarkable that with a thorn as long as one inch and a quarter, lying in the orbit right under the lid, which is always in motion, and with the iritis that ensued, the patient, who was a powerful agricultural labourer, did not feel himself out of sorts and only applied for help when, four months after the accident, chemosis set in. Evidently the tenonitis which was late in appearing had compelled him to seek relief and this was brought on by some sort of interference with the eye, although he denied it.

Repeated letters to him since February have not elicited any response from him. But I shall report it if I hear of any further change in the future.

\section{REMARKS REGARDING THE DISCUSSION UPON THE AETIOLOGY AND TREATMENT OF HYPOPYON ULCER}

BY

G. Herbert Burnham, M.D.Tor., F.R.C.S.Edin.

EMERITUS PROFESSOR OF OPHTHALMOLOGY AT UNIVERSITY OF TORONTO

AfTER reading the discussion on the treatment of hypopyon ulcer in the Transactions of the Ophthalmological Society of The United Kingdom, 192 $\mathrm{f}$, I beg to add to the list of remedies which have been brought forward, one which has not been in any respect alluded to; I refer to "The Combined Treatment"** which I have used in this disease for many years with great satisfaction.

When an ulcer of the cornea is so far advanced as to have hypopyon associated with it, then it is of course of a type that has always as a complication iritis more or less severe. "The Combined 'Treatment" consists of the hypodermic injection of pilocarpine and the internal administration of mercury and the

* "The Combined Treatment" of Diseases of the Eye, by G. Herbert Burnham, M.D.Tor,, F.R.C.S.Edin. Publisher, H. K. Lewis, 136, Gower Street, London, W.C. 1906. 